\title{
关于做好驻村精准扶贫工作的探讨
}

王应权

北京华安东会计师事务所有限责任公司

DOI:10.32629/ej.v2i6.307

[ 摘 要] 精准扶贫是在扶贫机制变革下产生的重要理念,其目的是加快扶贫工作的落实,增大贫困地区的建设速率,为新中国的建设提供动力。 不过在精准扶贫落实中仍存在着诸多问题,影响了扶贫工作的成效。基于此,本文就对精准扶贫工作进行分析探讨,并针对其中存在的问题给予 合理性建议。

[关键词] 驻村精准扶贫; 落实; 合理性建议

精准扶贫改变了贫困村落供给公共产品的方式, 促进单位联合, 再加 上社会力量的介入, 使贫困村落在公共产品上从供需脱节转变成供需无缝 衔接。通过驻村干部制度的建立, 也促成了贫困村落在公共物品供给上和 物质分配中的强有力监督, 提高了精准扶贫工作的效率。

\section{1 驻村帮扶制度的意义}

驻村帮扶制度在落实过程中, 可对现有的资源及人员进行整合和规划, 解决存在的供给不足问题。同时针对驻村的基本热点, 对现有规划设计予 以重新调整, 加大经济项目的建设力度。驻村帮扶制度为农村基层党组织 建设提供了保障。贫困村因自身硬件条件不理想, 存在严重的人才流失问 题, 导致区域内基层党组织更新较慢, 党组织人员普遍存在年龄偏大, 知识 结构不足、组织管理能力较弱等问题。但通过驻村帮扶制度的落实, 为基 层党组织的重建及更新提供了帮助, 在引进专业人才的基础上, 加强了对 现有人员的教育和培训, 完善相关制度体系, 提高党员的思想政治觉悟, 从 而推动基层党组织工作职能的落实, 为脱贫奠定基础。

再者, 驻村帮扶制度的落实改善了党群及干群的关系。驻村帮扶制度 坚持走群众路线, 要求党组织及相关干部群众深入到群众家中, 了解百姓 疾苦, 倾听百姓的声音, 并从百姓角度出发制定科学合理的措施, 解决群众 存在的问题, 以提升农村人民的经济水平, 加快新农村建设步伐。

\section{2 驻村干部精准扶贫中存在的问题}

2. 1 扶贫干部自身问题

驻村精准扶贫工作中, 大部分驻村干部都在上岗前经过了较为严格的 培训和考核, 具有较强的适应能力和执行能力。且驻村扶贫干部的思想觉 悟较高, 明确了解驻村扶贫工作的重要性, 确保各项政策措施的高效落实。 不过仍有小部分驻村干部对于扶贫工作的流程掌握不全, 地方性知识储备 不足, 使得驻村扶贫工作受到诸多限制。另外, 驻村干部在下乡后, 由于原 单位资源力量有限, 也会使工作受到一定制约, 进而影响扶贫项目的落实。

具体来说, 如果原单位是扶贫工作的先进机构, 会给予扶贫干部支持, 保证扶贫工作的有效开展, 避免资源的浪费; 而如果原单位自身资源较差, 或只属于普通部门, 则不仅在资金上无法给与有力支持, 还会存在只考虑 自身利益, 忽略驻村扶贫工作的情况, 加大驻村干部工作的难度。同时这种 情况下, 员工自身的工作积极性被打消, 影响精准化扶贫的效果。

\section{2 考核及监管机制不完善}

在驻村精准化扶贫中, 虽然制定了详细的考核、培训等管理制度, 但是 由于区域条件及管理方式的不同, 在落实各项制度上会存在一些不同, 出 现了表面化现象。一些农村在驻村扶贫工作开展中, 仅仅是以扶贫指标的 完成情况对工作成绩予以考核, 注重经济指标的完成情况, 忽略了区域的 教育、医疗及文化发展的评定，进而影响扶贫的整体效果。另外，考核机制 在监督扶贫工作组的扶贫开展进度比较容易, 但是却很难监测扶贫工作的
后期效果。

2. 3 扶贫措施单一

驻村扶贫工作团队来自各个不同部门, 在文化差异、业务处理等方面 存在一定差异, 在驻村扶贫工作落实中, 工作人员为了加强其效果, 往往会 采用较为保守的处理手段, 如带领民众实行项目挖掘, 资金筹集等, 降低了 扶贫工作的开展效率。

2. 4缺少工作积极性和主动性

在开展驻村精准扶贫工作中, 很多驻村干部都是由单位硬性指派的, 并没有依照工作要求做好人力资源的合理划分, 这使得工作人员存在消极 急工的情绪, 在工作开展中很难保持较高的工作热情和积极性, 扶贫工作 的表面化越来越严重, 员工对待工作的认真程度大打折扣, 阻碍了驻村扶 贫工作的推进。

\section{3 驻村精准扶贫工作的相关建议}

3. 1 促进交流, 实现资源共享

促进交流指的是加强部门间及区域间的交流, 在驻村精准扶贫工作中, 部门如果仅仅依靠单独运转是很难准确了解工作开展及落实情况的, 需要 通过各部门间的高效交流, 了解工作落实中可能或存在的问题, 然后通过 探讨制定合理改善措施, 保证扶贫工作的效率。同时部门间的及时交流也 能够帮助工作人员转变思想, 创新管理模式, 实现资源优化配置。且区域交 流能够增大跨地区交流协作力度, 在满足因地制宜要求的基础上, 将全国 贫困户连接起来, 这样不仅会使扶贫工作有更多的新思路、新方法, 更重要 的是也会激发贫困户的内生动力。当个体的努力转化为一个团队的协作时, 扶贫效果将得到较大改进。

3.2 明确考核评价指标

以往一票否决的评价指标虽然能够调动驻村干部的工作积极性, 但也 给干部人员自身带来了较大压力。这种评价方式主要是以贫困户对服务满 意度情况来评定工作人员自身能力的, 但一些贫困户经常会提出较为苛刻 甚至无理的请求, 如果不能满足贫困户需求, 则会降低其满意度, 给工作人 员带来较大影响。另外, 一些扶贫干部在日常工作中表现不积极, 但在领导 检查中则是相反状态, 最终评价结果不准确, 产生较大偏差。再者, 扶贫工 作人员平时競兢业业, 但是因为没有满足一些村民的不合理要求, 村民的 “不满意” 反馈就会影响扶贫工作人员的实际工作效果评价。所以, 建立 多方面多层次的精准扶贫考核也是势在必行的。

3. 3统筹规划

一方面要结合贫困村的基本情况及政策要求, 制定合理的发展规划, 对现有资源进行准确划分, 加大基础设施、公共服务设施的建设力度。另 一方面做到因地制宜、因户制宜, 真正了解贫困户的需求, 保证政策及扶贫 方案的精准性, 且在扶贫工作开展中, 确保工作职能的有效落实, 充分发挥 


\title{
档案信息化管理的归档策略与管理创新
}

\author{
王小雨 \\ 洮南市审计局 \\ DOI:10.32629/ej.v2i6.279
}

[摘 要] 随着我国科技水平的提升,档案管理方式也开始逐渐呈现出多样化发展的趋势,档案信息化管理是现阶段时代发展的必然走向。对于 传统的档案管理方式来说, 在实际应用的过程中往往不能满足现阶段审计局工作展开的实际需求,使得整体工作效率以及工作质量受到了一定 影响。在大数据时代,信息化档案管理模式的应用势在必行,在对此种管理方式进行应用的时候,其优势主要体现在可以有效提升工作效率,从而 使审计工作的展开更加顺利。基于此,本文尝试对档案信息化管理的归档策略与管理创新进行了分析。

[关键词] 档案信息化管理; 归档策略; 管理创新

对于审计局而言, 由于其自身工作性质具有一定的特殊性, 在工作展 开的过程中对于档案管理的整体质量以及效率会有很高的要求。审计工作 是一项相对繁琐的工作, 在实际展开的过程中会涉及到多个环节步骤, 并 且对相关从业人员自身的专业素质有很高的要求。在新形势下, 对档案信 息化的管理理念进行全面落实是非常有必要的, 利用信息化管理的理念可 以更好的实现对档案的归档, 同时也有利于对管理工作进行优化创新。

\section{1 档案信息化管理模式全面落实应用的重要性}

对于市审计局来说, 由于其工作性质具有一定的特殊性, 所涉及到的 工作内容较多。其具体职责主要包括主管全市审计工作、负责审计方面的 地直各事业单位的财务收支、市重点项目的预算投资报告审计等等, 其工 作内容具有多样性的特点 ${ }^{[1]}$ 。因此, 市审计局在日常工作运转的过程中会 产生的大量的信息数据档案资料, 如何对其进行分类以及管理是非常重要 的, 会直接关系到审计局自身工作运转的准确性以及效率。对于传统的人 工或者半人工档案管理以及分类工作模式来说, 在实际展开的过程中很可 能会影响到审计局工作的正常运行。在现阶段的时代背景之下, 大数据信 息技术的应用已经越来越普及,很多传统运行行业都开始积极与信息技术 进行结合, 都有效的起到了促进行业综合发展的作用 ${ }^{[2]}$ 。对于市审计局来 说, 由于工作过程中所涉及到的各个环节层次较多, 主要包括以下方面。有 关于市重点项目的预算投资以及收益统计方面的工作 ; 同时也有对相关法 律规定的事业单位制度落实情况的审计评价工作, 还有对各个直属事业单 位以及下属单位收支情况进行统计。由此可以看出市审计局在实际工作展

扶贫干部的带头作用, 以推动精准化扶贫工作的开展, 真正解决贫困户存 在的问题。帮助所驻贫困村深化村情认识, 理清发展思路, 依据劳动力资源 以及实际需要, 制定符合村情实际的产业发展规划和基础设施、公共服务 配套建设规划。

3. 4 创新扶贫措施, 增大经济效益

在驻村扶贫工作开展中, 除了要做到因地制宜开展扶贫工作外, 还应 结合贫困村现有的优势和特征加大特色产业的创建力度, 提高贫困村的经 济收入, 且创新扶贫措施, 提高贫困户的经济水平。或者还可通过节能培养 等方式来增大贫困户的就业率, 改进扶贫工作的质量。再者, 还需加大发展 力度, 整合人社、扶贫、农牧、旅游等部门培训资源, 提高培训的针对性和 实效性, 确保每个贫困户至少有 1 名劳动力接受培训, 并鼓励支持致富能 人、经纪人带领贫困群众外出打工、增加收入, 从而拓宽就业渠道, 增强就 业创业能力。

3. 5 健全和完善扶贫干部激励制度

激励机制的建立和完善能够很好的调动扶贫干部工作的积极性和主
开的过程中, 所涉及到的工作内容性质不一, 这也势必会产生大量的文档 资料, 在对文档资料展开管理工作的时候应该与现阶段市审计局的工作实 际需求相符合, 这样才能够保证审计局的整体运行质量。

\section{2 当前档案信息化管理工作中存在的问题}

2. 1 管理工作人员的思想意识有待提升

从现阶段审计局档案信息化管理工作展开的实际情况来看, 部分档案 管理工作人员自身的管理思想意识有待进一步提升。在档案管理工作展开 的过程中, 很多管理工作人员由于长期受到传统的档案管理理念的影响, 现阶段应用信息化管理方式展开管理工作的时候, 往往很难转变传统的档 案管理思想理念, 从而导致了管理工作在实际展开的过程中经常会出现与 工作目标不相符的情况 ${ }^{\left[{ }^{3}\right]}$ 。同时还有一部分档案管理工作人员在展开归档 工作的时候, 缺乏创新意识以及开放性管理的意识, 从而导致档案归档工 作展开的整体效率以及准确性受到了较为严重的影响。对于这些档案管理 思想较为传统的工作人员来说, 往往在主观意识上认为信息化档案管理与 传统的档案管理工作理念差别不大, 也正是由于这种心理状态的存在导致 了信息化档案管理工作在实际展开的过程中往往是 “旧瓶装新酒” , 并没 有有效起到提升档案管理效率以及质量的作用, 导致了档案管理工作的创 新没有得到很好的体现。同时, 信息化档案管理的方式在实际落实的过程 中, 往往只是在部分部门以及工作领域开放, 并没有实现对信息化档案管 理理念的全面落实。

2. 2 技术更新存在滞后的情况 扶贫工作的效率。同时在激励制度完善中, 还可通过升迁变动、技术考核 及评定等方式帮助扶贫干部树立正确的工作意识, 减少负面情绪的产生, 注重扶贫部门人员的充足性, 降低人才流失带来的影响。

\section{4 结语}

总之, 为了推动驻村精准扶贫工作的有序开展, 相关部门及人员不但 要完善自身专业素养及意识水平, 还需结合贫困村的实际情况, 制定合理 的扶贫制度和方案, 并调动社会及民众的参与积极性, 以此彻底提升贫困 村的经济水平, 为我国建设贡献力量。

\section{[参考文献]}

[1]曹康.关于做好驻村精准扶贫工作的探讨[J].农技服务,2017,34(6):191. [2]陈然, 张琪琪,谭昌顺.嵌入与帮扶:驻村工作队在农村精准扶贫工作 中的效度与限度研究 [J]. 黑河学刊,2018,(04):9-12.

[3] 李杰.浅谈驻村帮扶工作如何做好扶贫解困工作 [J]. 传播力研 究,2017,1(02):102-103+105. 